\title{
Analisa Algoritma SHA-256 Untuk Mendeteksi Orisinalitas Citra Digital
}

\author{
Imam Saputra1, Surya Darma Nasution² \\ STMIK Budi Darma ${ }^{12}$ \\ Jl. Sisingamangaraja No. 338, Medan - Sumatera Utara, (061) 7875998 \\ saputraimam69@gmail.com ${ }^{1}$, darmashadow@gmail.com²
}

\begin{abstract}
In the digital era, changing human habits, one of the changing habits is in applying for someone's job. Before the digital era, applying for a job by sending an application to the address of the destination company. In the digital era, as now, applying for jobs can be done boldly, and sent in softcopy. This softcopy file forms a digital image that can be easily manipulated. How would it be difficult for the receiving committee to determine the original file with the manipulated a file. With the existing questions, we need a technique that can be used to request the originality of the job application file. One technique that can be used is the hash function that exists in cryptography. The hash function is a one-way function that can be used to find a message. If applied to digital images, the originality of the image can be recognized. The algorithm in the hash function used is Secure Hash Algorithm 256 (SHA256) until now this algorithm cannot be solved by cryptanalysts. By applying the Secure Hash Algorithm 256 algorithm, it will make it easier and faster to access the originality of digital images.
\end{abstract}

Keywords : Hash Function, SHA-256, Cryptograhphy, Digital Image

\begin{abstract}
Abstrak-Di era serba digital telah mengubah kebiasaan manusia, salah satu kebiasaan yang berubah adalah dalam melamar suatu pekerjaan. Sebelum berada pada era digital, melamar pekerjaan dengan cara mengirimkan berkas lamaran ke alamat perusahaan yang dituju. Di era digital seperti sekarang ini melamar pekerjaan dapat dilakukan secara daring, dan berkas dikirim dalam bentuk softcopy. Berkas dalam bentuk softcopy ini berupa citra digital yang dapat dengan mudah dilakukan manipulasi. Sehingga akan menyulitkan panitia penerima lamaran kerja untuk membedakan berkas yang orisinal dengan berkas yang telah dimanipulasi. Dengan permasalahan yang ada maka dibutuhkan suatu teknik yang dapat digunakan untuk mendeteksi orisinalitas dari berkas lamaran kerja. Salah satu teknik yang dapat digunakan adalah dengan fungsi hash yang ada dalam kriptografi. Fungsi hash merupakan fungsi satu arah yang dapat digunakan untuk mengetahui otentikasi suatu pesan. Jika diterapkan pada citra digital maka dapat diketahui orisinalitas citra tersebut. Algoritma dalam fungsi hash yang digunakan adalah Secure Hash Algorithm 256 (SHA256), sampai saat ini algoritma ini belum dapat dipecahkan oleh kriptanalis. Dengan menerapkan algoritma Secure Hash Algorithm 256 akan memudahkan dan mempercepat untuk mendeteksi orisinalitas citra digital.
\end{abstract}

Kata Kunci : Fungsi Hash, SHA-256, Kriptografi, Citra Digital

\section{PENDAHULUAN}

Di era yang serba digital telah banyak mengubah kebiasaan dalam kehidupan sehari-hari, berkas-berkas dalam bentuk hardcopy sudah jarang digunakan karena memiliki banyak kelemahan. Salah satunya dalam hal pengiriman berkas yang membutuhkan waktu yang cukup lama. Sebelum adanya era digital ketika seseorang akan melamar suatu pekerjaan maka berkas lamarannya di kirim dalam bentuk hardcopy, tetapi setelah adanya era digital ini berkas lamaran pekerjaan 
dapat dikirim melalui jaringan internet dalam bentuk softcopy. Dengan demikian maka proses pengiriman dengan waktu yang singkat. Dengan adanya keuntungan yang dimiliki oleh pengiriman berkas lamaran kerja yang dapat dikirim melalui jaringan internet juga memiliki banyak kelemahan, salah satunya adalah masalah keaslian berkas-berkas yang dikirim dalam bentuk softcopy tersebut. Berkas yang penting untuk diketahui keasliannya atau orisinalitas dari berkas tersebut adalah softcopy ijazah dan transkrip nilai. Tahapan awal yang dilakukan oleh panitia penerima lamaran kerja adalah seleksi berkas dengan cara menyeleksi berkas sesuai dengan persyaratan minimalnya. Untuk melakukan pengiriman berkas lamaran tersebut biasanya pelamar melakukan pemindaian ijazah ataupun transkrip nilai dan hasil dari pemindaian tersebut berupa citra digital. Apabila dilakukan perubahan ataupun manipulasi softcopy berkas yang dikirim oleh pelamar akan menyulitkan panitia untuk mengetahui keaslian atau softcopy berkas yang dikirimkan oleh para pelamar.

Saat ini ada banyak perangkat lunak dapat digunakan untuk memanipulasi citra digital. Dengan kecanggihan perangkat lunak tersebut bisa membuat citra digital yang dimanipulasi tidak memiliki kejanggalan sehingga sangat sulit untuk dideteksi melalui visual manusia. Oleh karena itu dibutuhkan suatu cara yang dapat digunakan mendeteksi keaslian atau orisinalitas dari citra hasil pemindaian berkas lamaran kerja tersebut. Setiap file digital memiliki metadata yang berisi informasi tentang file tersebut. Metadata dari file citra digital biasanya berisi resolusi citra, dimensi citra, tanggal pembuatan serta ukuran dari citra tersebut. Dengan adanya metadata tersebut dapat dimanfaatkan untuk menyimpan sebuah kode yang digunakan untuk mendeteksi orisinalitas atau keaslian dari citra tersebut. Jika ada perbedaan kode tersebut maka citra tersebut tidak otentik, ataupun telah terjadi perubahan pada citra tersebut. Untuk mendapatkan kode yang dapat dimanfaatkan untuk mendeteksi keaslian dari citra digital maka dapat menggunakan fungsi hash. Fungsi hash dapat digunakan untuk mengecek keutuhan dari sebuah pesan dan juga otentikasi pesan tersebut, dalam hal ini pesan yang dimaksud dalam bentuk citra digital. Fungsi hash merupakan fungsi satu arah yang menghasilkan keluaran berupa nilai hash atau messsage digest. Salah satu fungsi hash yang bisa digunakan adalah SHA (Secure Hash Algorithm) yang dibuat oleh NIST. SHA-2 mengalami perubahan yang signifikan dibandingkan dengan SHA-1. SHA-2 memiliki 6 varian yaitu SHA-224, SHA-256, SHA-384, SHA-512, SHA512/224, SHA-512/256 yang memiliki keluaran nilai hash 32 bit [1]. SHA-256 dapat diimplementasikan untuk mendeteksi keaslian citra digital dengan cara mengubah citra tersebut menjadi nilai hash sepanjang 32 bit. Algoritma SHA-256 memiliki tingkat kompleksitas yang sama dengan algoritma MD5 [2]. SHA-256 dapat diterapkan pada berbagai sistem, salah satunya dapat diterapkan untuk memverifikasi sistem yang berbasis FPGA [3].

\section{METODOLOGI PENELITIAN}

\subsection{Kerangka Penelitian}

Metodologi penelitian ini digambarkan dalam bentuk kerangka kerja (framework). Kerangka kerja merupakan struktur konseptual dasar yang digunakan untuk memecahkan atau menangani suatu masalah yang kompleks. Berdasarkan pedoman dari langkah kerja inilah penelitian akan dilakukan. 


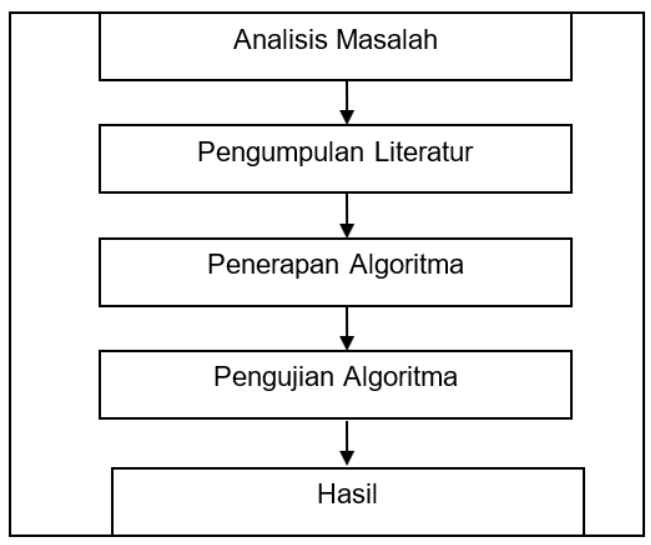

Gambar 1. Kerangka Kerja

\subsection{Citra Digital}

Citra merupakan adalah representasi atau gambaran, kemiripan atau tiruan dari suatu objek [4]. Citra terbagi menjadi 2 bagian yaitu citra analog dan citra digital. Citra analog merupakan citra yang memiliki sifat kontinu, seperti gambar pada layar televisi, foto sinar-X, gambar yang tercetak di kertas, lukisan, pemandangan, hasil CT-scan, gambar-gambar yang tercetak pada pita kaset dan lain sebagainya [4]. Ada dua cara yang dapat digunakan untuk mengubah citra analog menjadi citra digital yaitu dengan cara sampling dan kuantisasi. Sampling merupakan transformasi citra kontinu menjadi citra digital menggunakan cara membagi citra analog menjadi $\mathrm{M}$ kolom dan $\mathrm{N}$ baris dan menjadi citra diskrit sedangkan kuantisasi adalah transformasi intensitas citra analog yang bersifat kontinu ke daerah intensitas diskrit.

Citra digital disimpan dalam bentuk bilangan biner. Secara umum citra digital adalah sebuah larik ataupun array dua dimensi yang berisi nilai-nilai bilangan real maupun bilangan kompleks yang digambarkan dengan deretan bit tertentu [5]. Secara matematis citra digital didefinisikan sebagai fungsi $f(x, y)$ yang berukuran $M$ baris dan $N$ kolom dengan sumbu $x$ dan sumbu $y$ adalah koordinat spasial dan $f$ sebagai amplitudo di koordinat $(x, y)$ yang dinamakan intensitas ataupun tingkat keabuan dititik tersebut $\operatorname{dan} f$ bernilai diskrit [5].

\subsection{Kriptografi}

Jika ingin mengirimkan sebuah pesan maka pesan tersebut harus sampai kepada penerima dengan aman dan pesan tersebut tidak dapat dibaca oleh pihak yang tidak berwenang. Oleh sebab itu dibutuhkan sebuah teknik untuk mengamankan pesan tersebut yang disebut teknik kriptografi. Kriptografi adalah ilmu dan seni yang digunakan untuk menjaga keamanan pesan [6]. Kata seni yang dimaksud dalam pengertian kriptografi di atas berasal dari fakta dalam sejarah bahwa pada zaman dahulu setiap orang mempunyai cara tersendiri dan unik untuk dapat merahasiakan pesan yang akan disampaikan. Cara tersebut unik dan memiliki estetika sendiri sehingga kriptografi dapat berkembang sebagai seni untuk merahasiakan pesan. 


\subsection{Fungsi Hash}

Fungsi satu arah sering disebut juga fungsi hash, message digest, fingerprint, kompresi dan message authentication code. Fungsi ini biasanya digunakan untuk mengambil sidik jari suatu pesan [7]. Fungsi hash adalah fungsi yang menerima masukan string dengan panjang sembarang dan mengonversinya menjadi string keluaran yang panjangnya tetap [6]. Pesan yang telah diubah menjadi message digest tidak dapat dikembalikan lagi menjadi pesan semula. Pesan yang berbeda akan menghasilkan nilai hash yang berbeda. Sifat dari hash adalah sebagai berikut:

a. Fungsi $\mathrm{H}$ dapat diterapkan pada blok data berukuran berapa saja

b. H menghasilkan nilai hash dengan panjang tetap

c. $\mathrm{H}(\mathrm{x})$ mudah dihitung untuk setiap nilai $\mathrm{x}$ yang diberikan

d. Untuk setiap $\mathrm{h}$ yang diberikan, tidak mungkin menemukan $\mathrm{x}$ sedemikian sehingga $H(x)=h$

e. Untuk setiap x yang diberikan, tidak mungkin mencari y tidak sama sedemikian sehingga $\mathrm{H}(\mathrm{y})=\mathrm{H}(\mathrm{x})$

f. Tidak mungkin mencari pasangan $x$ dan $y$ sedemikian sehingga $H(x)=H(y)$

\subsection{SHA-256}

Secure Hash Algorithm (SHA) 256 merupakan fungsi hash yang umum digunakan, sampai saat ini belum ada yang dapat memecahkan algoritma fungsi hash SHA-256. Algoritma SHA-256 memiliki 8 langkah pengerjaan yaitu sebagai berikut [2]:

a. Tambahkan bit Padding

Pesan diisi sehingga panjangnya kongruen dengan 448, modulus 512. Padding 1 bit ditambahkan di akhir pesan, diikuti oleh banyaknya nol yang diperlukan sehingga panjang bit sama dengan 448 modulus 512 .

b. Panjang Append

Representasi panjang pesan 64 bit ditambahkan pada hasil akhirnya, langkah ini untuk membuat panjang pesan kelipatan 512 bit.

c. Parsing Pesan

Pesan padding diuraikan menjadi $N$ blok pesan 512 bit, $M(1), M(2), \ldots M(N)$, dengan menambahkan blok 64 bit.

d. Inisialisasi Nilai Hash

Nilai hash awal, H(0) diatur, terdiri dari delapan kata 32 bit, dalam bentuk heksadesimal.

Tabel 1. Initial Hash Value

\begin{tabular}{|r|c|r|c|r|c|r|r|}
\hline Variabel & Hash Value & Variabel & Hash Value & Variabel & Hash Value & Variabel & Hash Value \\
\hline$H_{0}(0)$ & $=6 \mathrm{~A} 09 \mathrm{E} 667$ & $H_{1}(0)$ & $=\mathrm{BB} 67 \mathrm{EA} 85$ & $H_{2}(0)$ & $=3 \mathrm{C} 6 \mathrm{EF} 372$ & $H_{3}(0)$ & $=\mathrm{A} 54 \mathrm{FF} 53 \mathrm{~A}$ \\
\hline$H_{4}(0)$ & $=510 \mathrm{E} 527 \mathrm{~F}$ & $H_{5}(0)$ & $=9 \mathrm{~B} 05688 \mathrm{C}$ & $H_{6}(0)$ & $=1 \mathrm{~F} 83 \mathrm{D} 9 \mathrm{AB}$ & $H_{7}(0)$ & $=5 \mathrm{BE} 0 \mathrm{CD} 19$ \\
\hline
\end{tabular}

Sumber : Federal Information Processing Standards Publications, 2002 [8]

e. Mempersiapkan jadwal pesan

SHA-256 menggunakan jadwal pesan enam puluh empat kata 32 bit, kata-kata dari jadwal pesan diberi label W0, W1, ..., W63.

$$
W t=\left\{\begin{array}{cc}
M_{t}^{(t)} & 0 \leq t \leq 15 \\
\sigma_{1}^{(256)}\left(W_{i-2}\right)+W_{i-7}+\sigma_{0}^{(256)}\left(W_{i-15}\right)+W_{i-16}, & 16 \leq t \leq 63
\end{array}\right.
$$


Di mana :

$\sigma_{1}^{(256)}\left(W_{i-2}\right)=\left(\left(W_{i-2}\right) R O T R\right.$ 17 $) \oplus\left(\left(W_{i-2}\right) R O T R 19\right) \oplus\left(\left(W_{i-2}\right) S H R 10\right)$

$\sigma_{0}^{(256)}\left(W_{i-15}\right)=\left(\left(W_{i-15}\right) R O T R 7\right) \oplus\left(\left(W_{i-15}\right) R O T R 18\right) \oplus\left(\left(W_{i-15}\right) S H R 3\right)$

Keterangan:

$W t \quad=$ Blok pesan yang baru

Mt = Blok pesan yang lama

$W_{i-2} \quad=$ Blok pesan dari $W$ ke i-2

$W_{i-15}=$ Blok pesan dari $W$ ke i -15

ROTR = Rotate Right

SHR = Shift Right

$\oplus \quad=$ Operator $X O R$

f. Inisialisasi delapan variabel kerja $a, b, c, d, e, f, g$, dan $h$ dengan nilai $h a s h(\mathrm{i}-1)$ For $\mathrm{t}=0$ to 63

$$
\left\{\begin{array}{l}
T_{1}=h+\sum_{1}^{(256)}(e)+\operatorname{Ch}(e, f, g)+K_{1}^{(256)}+W_{t} \\
T_{2}=\sum_{0}^{(256)}(a)+\operatorname{Maj}(a, b, c) \\
h=g \\
g=f \\
f=e \\
\quad e=d+T_{1} \\
\quad d=c \\
\quad c=b \\
b=a \\
\left.a=T_{1}+T_{2}\right\}
\end{array}\right.
$$

Di mana :

$\sum_{1}^{(256)}(e)=($ e ROTR 6$) \oplus($ e ROTR 11$) \oplus($ e ROTR 25$)$
$\sum_{0}^{(256)}(a)=($ a ROTR 2$) \oplus($ a ROTR 13$) \oplus($ a ROTR 22$)$

$\operatorname{Ch}(e, f, g)=\left(e^{\wedge} f\right) \oplus\left(\sim e^{\wedge} g\right)$

$\operatorname{Maj}(a, b, c)=\left(a^{\wedge} b\right) \oplus\left(a^{\wedge} c\right) \oplus\left(b^{\wedge} c\right)$

$a, b, c, d, e, f, g, h=$ Variabel yang berisi pesan heksadesimal

$K_{1}(256) \quad=$ Konstansta SHA-256

ROTR = Rotate Right

$\oplus \quad=$ Operator $X O R$

$\wedge \quad=$ Operator $A N D$

Tabel 2. Konstanta SHA-256

\begin{tabular}{|c|c|c|c|c|c|c|c|}
\hline 428A2F98 & 71374491 & B5C0FBCF & E9B5DBA5 & 3956C25B & 59F111F1 & 923F82A4 & AB1C5ED5 \\
\hline D807AA98 & 12835B01 & 243185BE & 550C7DC3 & 72BE5D74 & 80DEB1FE & 9BDC06A7 & C19BF174 \\
\hline E49B69C1 & EFBE4786 & 0FC19DC6 & 240CA1CC & 2DE92C6F & 4A7484AA & 5CB0A9DC & 76F988DA \\
\hline 983E5152 & A831C66D & B00327C8 & BF597FC7 & C6E00BF3 & D5A79147 & 06CA6351 & 14292967 \\
\hline 27B70A85 & 2E1B2138 & 4D2C6DFC & 53380D13 & 650A7354 & 766A0ABB & 81C2C92E & 92722C85 \\
\hline A2BFE8A1 & A81A664B & C24B8B70 & C76C51A3 & D192E819 & D6990624 & F40E3585 & 106AA070 \\
\hline 19A4C116 & 1E376C08 & 2748774C & 34B0BCB5 & 391C0CB3 & 4ED8AA4A & 5B9CCA4F & 682E6FF3 \\
\hline 748F82EE & 78A5636F & 84C87814 & 8CC70208 & 90BEFFFA & A4506CEB & BEF9A3F7 & C67178F2 \\
\hline
\end{tabular}

Sumber : Federal Information Processing Standards Publications, 2002 [8] 
g. Menjumlahkan hasil akhir $a, b, c, d, e, f, g, h$ dengan inisial hash value $H^{(i)}$

\begin{tabular}{|c|c|c|c|c|c|c|c|}
\hline$H_{0}(i)$ & $=a+H_{0}(i)$ & $H_{1}{ }^{(i)}$ & $=b+H_{1}(i)$ & $H_{2}{ }^{(i)}$ & $=c+H_{2}(i)$ & $H_{3}{ }^{(i)}$ & $=d+H_{3}{ }^{(i)}$ \\
\hline$H_{4}{ }^{i}$ & $=e+H_{4}{ }^{i}$ & $H_{5}(i)$ & $=f+H_{5}(i)$ & $H_{6}(i)$ & $=g+H_{6}(i)$ & $H_{7}{ }^{(i)}$ & $=h$ \\
\hline
\end{tabular}

\section{h. Output}

Setelah mengulangi langkah 1 hingga 4 sebanyak $\mathrm{N}$ kali, fungsi hash yang dihasilkan adalah sebagai berikut :

$$
H_{0}^{(N)}\left\|H_{1}^{(N)}\right\| H_{2}^{(N)}\left\|H_{3}^{(N)}\right\| H_{4}^{(N)}\left\|H_{5}^{(N)}\right\| H_{6}^{(N)} \| H_{7}^{(N)}
$$

\section{HASIL DAN PEMBAHASAN}

\subsection{Analisa Algoritma SHA-256}

Yang menjadi objek pada penelitian ini adalah dokumen citra digital hasil pemindaian dari ijazah dan transkrip nilai. Dokumen hasil pemindaian ini berformat jpg dengan resolusi spasial 300 dpi. Untuk memudahkan proses analisa maka diambil sampel dari hasil pemindaian ijazah dan transkrip nilai tersebut berukuran 6 × 6 piksel pada kanal merah saja dan nilai piksel tersebut diambil menggunakan aplikasi MatlabR2017.

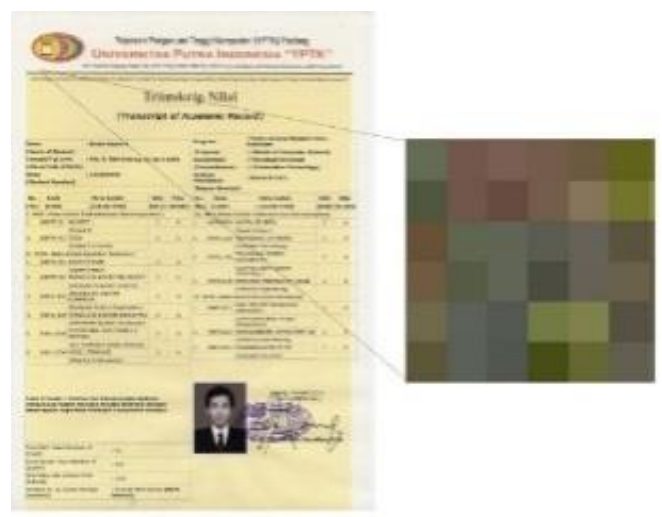

Gambar 2. Nilai Piksel Citra Sampel

Berikut ini adalah langkah-langkah penerapan algoritma SHA-256 untuk mendeteksi orisinalitas citra hasil pemindaian ijazah dan transkrip nilai. Sebelum menerapkan algoritma SHA-256 dilakukan terlebih dahulu penyesuaian input berupa bilangan biner. Untuk itu, nilai piksel dari citra input diubah ke dalam bilangan biner.

Tabel 3. Nilai Input biner

\begin{tabular}{|l|l|l|l|l|l|}
\hline 01001111 & 01100000 & 01101111 & 01101001 & 01101001 & 01100010 \\
\hline 01100100 & 01101110 & 01101101 & 01111001 & 01110011 & 01101011 \\
\hline 01011110 & 01011000 & 01101010 & 01100001 & 01110000 & 01111010 \\
\hline 01110010 & 01100000 & 01101001 & 01100110 & 01100001 & 01101001 \\
\hline 01101000 & 01101001 & 01011010 & 01100010 & 01001100 & 01100101 \\
\hline 01100000 & 01101111 & 01100000 & 01010110 & 01110011 & 01110100 \\
\hline
\end{tabular}


a. Penambahan Padding Bit

Dari tabel 4 di atas diketahui bahwa panjang $\mathrm{M}=288$ bit. Proses berikutnya adalah dengan menambahkan padding bit 1 dan sisanya 0 sejumlah $k$, dengan persamaan sebagai berikut :

$k=l+1 \equiv 448 \bmod 512$

$k=288+1 \equiv 448 \bmod 512$

$k=289 \equiv 448 \bmod 512$

$k=448-229$

$k=159$

Maka banyaknya padding bit 0 yang ditambahkan adalah 159 bit.

Tabel 4. Penambahan Padding Bit

\begin{tabular}{|l|l|l|l|l|l|l|l|}
\hline 01001111 & 01100000 & 01101111 & 01101001 & 01101001 & 01100010 & 01100100 & 01101110 \\
\hline 01101101 & 01111001 & 01110011 & 01101011 & 01011110 & 01011000 & 01101010 & 01100001 \\
\hline 01110000 & 01111010 & 01110010 & 01100000 & 01101001 & 01100110 & 01100001 & 01101001 \\
\hline 01101000 & 01101001 & 01011010 & 01100010 & 01001100 & 01100101 & 01100000 & 01101111 \\
\hline 01100000 & 01010110 & 01110011 & 01110100 & 10000000 & 00000000 & 00000000 & 00000000 \\
\hline 00000000 & 00000000 & 00000000 & 00000000 & 00000000 & 00000000 & 00000000 & 00000000 \\
\hline 00000000 & 00000000 & 00000000 & 00000000 & 00000000 & 00000000 & 00000000 & 00000000 \\
\hline
\end{tabular}

\section{b. Penambahan Panjang Append}

Penambahan panjang append dilakukan dengan penambahan panjang pesan sebanyak 64 bit di akhir. Panjang pesan adalah 288 bit sehingga ditambahkan panjang append sebagai berikut:

Tabel 5. Penambahan Panjang Append

\begin{tabular}{|l|l|l|l|l|l|l|l|}
\hline 01001111 & 01100000 & 01101111 & 01101001 & 01101001 & 01100010 & 01100100 & 01101110 \\
\hline 01101101 & 01111001 & 01110011 & 01101011 & 01011110 & 01011000 & 01101010 & 01100001 \\
\hline 01110000 & 01111010 & 01110010 & 01100000 & 01101001 & 01100110 & 01100001 & 01101001 \\
\hline 01101000 & 01101001 & 01011010 & 01100010 & 01001100 & 01100101 & 01100000 & 01101111 \\
\hline 01100000 & 01010110 & 01110011 & 01110100 & 10000000 & 00000000 & 00000000 & 00000000 \\
\hline 00000000 & 00000000 & 00000000 & 00000000 & 00000000 & 00000000 & 00000000 & 00000000 \\
\hline 00000000 & 00000000 & 00000000 & 00000000 & 00000000 & 00000000 & 00000000 & 00000000 \\
\hline 00000000 & 00000000 & 00000000 & 00000000 & 00000000 & 00000000 & 00000001 & 00100000 \\
\hline
\end{tabular}

\section{c. Parsing Pesan}

Pada kasus ini panjang pesan tidak lebih dari 512 sehingga hanya menghasilkan 1 blok 512 bit yaitu $M^{(0)}$. Tahap selanjutnya adalah melakukan parsing pesan dengan membagi setiap blok 512 bit menjadi 16 blok berukuran 32 bit.

Tabel 6. Parsing Pesan

\begin{tabular}{|c|c|c|c|c|c|}
\hline$M_{0}(0)$ & : & $\begin{array}{l}0100111101100000 \\
0110111101101001\end{array}$ & $M_{1}(0)$ & : & $\begin{array}{l}011010010110001001100100011011 \\
10\end{array}$ \\
\hline$M_{2}(0)$ & : & $\begin{array}{l}011011010111100101110011 \\
01101011\end{array}$ & $M_{3}(0)$ & : & $\begin{array}{l}010111100101100001101010011000 \\
01\end{array}$ \\
\hline$M_{4}(0)$ & : & $\begin{array}{l}011100000111101001110010011000 \\
00\end{array}$ & $M_{5}(0)$ & : & $\begin{array}{l}011010010110011001100001011010 \\
01\end{array}$ \\
\hline$M_{6}(0)$ & : & $\begin{array}{l}01101000 \\
011010010101101001100010\end{array}$ & $M_{7}(0)$ & : & $\begin{array}{l}010011000110010101100000011011 \\
11\end{array}$ \\
\hline
\end{tabular}




\begin{tabular}{|l|l|l|l|l|l|}
\hline$M_{8}(0)$ & $:$ & $\begin{array}{l}011000000101011001110011011101 \\
00\end{array}$ & $M_{9}(0)$ & $:$ & $\begin{array}{l}100000000000000000000000000000 \\
00\end{array}$ \\
\hline$M_{10^{(0)}}$ & $:$ & 000000000000000000000000000000 \\
00 & $M_{11^{(0)}}$ & $:$ & $\begin{array}{l}000000000000000000000000000000 \\
00\end{array}$ \\
\hline$M_{12^{(0)}}$ & $: \begin{array}{l}00000000000000000000000000000 \\
00\end{array}$ & $M_{13^{(0)}}$ & $:$ & $\begin{array}{l}000000000000000000000000000000 \\
00\end{array}$ \\
\hline$M_{14^{(0)}}:$ & $\begin{array}{l}000000000000000000000000000000 \\
00\end{array}$ & $M_{15^{(0)}}$ & $:$ & $\begin{array}{l}000000000000000000000001001000 \\
00\end{array}$ \\
\hline
\end{tabular}

d. Inisialisasi Nilai Hash

Setelah proses parsing pesan maka langkah selanjutnya adalah inisialisasi nilai hash di mana nilai ini merupakan sebuah ketentuan yaitu :

Tabel 7. Initial Hash Value

\begin{tabular}{|r|c|r|c|r|c|r|c|}
\hline Variabel & Hash Value & Variabel & Hash Value & Variabel & Hash Value & Variabel & Hash Value \\
\hline$H_{0}(0)$ & $=6 \mathrm{~A} 09 \mathrm{E} 667$ & $H_{1}(0)$ & $=\mathrm{BB} 67 \mathrm{EA} 85$ & $H_{2}(0)$ & $=3 \mathrm{C} 6 \mathrm{EF} 372$ & $H_{3}(0)$ & $=\mathrm{A} 54 \mathrm{FF} 53 \mathrm{~A}$ \\
\hline$H_{4}(0)$ & $=510 \mathrm{E} 527 \mathrm{~F}$ & $H_{5}(0)$ & $=9 \mathrm{~B} 05688 \mathrm{C}$ & $H_{6}(0)$ & $=1 \mathrm{~F} 83 \mathrm{D} 9 \mathrm{AB}$ & $H_{7}(0)$ & $=5 \mathrm{BE} 0 \mathrm{CD} 19$ \\
\hline
\end{tabular}

e. Penjadwalan Pesan

Kemudian dilakukan proses penjadwalan pesan, langkah ini diawali dengan mengubah setiap blok pesan menjadi bilangan heksadesimal dengan ketentuan sebagai berikut :

$$
W t=\left\{\begin{aligned}
M_{t}^{(t)} & 0 \leq t \leq 15 \\
\sigma_{1}^{(256)}\left(W_{i-2}\right)+W_{i-7}+\sigma_{0}^{(256)}\left(W_{i-15}\right)+W_{i-16}, & 16 \leq t \leq 63
\end{aligned}\right.
$$

Tabel 8. Penjadwalan Pesan

\begin{tabular}{|c|c|c|c|c|c|c|c|}
\hline 4F606F69 & 6962646E & 6D79736B & 5E586A61 & 707A7260 & 69666169 & 4C65606F & 4C656F \\
\hline 60567374 & 80000000 & 00000000 & 00000000 & 00000000 & 00000000 & 00000000 & 00000120 \\
\hline 18458186 & F1C56C43 & B25F3BC3 & CC660898 & 32D405C0 & CE182B88 & 79CDBB87 & ED495557 \\
\hline CDC92068 & B299951B & 807015AD & 2AD60F3A & D65B97BB & 403EA139 & E6B05C80 & C1CE665A \\
\hline B394B55B & D1EB82CF & 5391D3AD & DB1B2C81 & 49879567 & 17DA8AA1 & 5ACF9149 & 3517EFA5 \\
\hline 1EC0C640 & 5EBC651C & CA3CE603 & BB20E07F & B0F32F26 & 116867D3 & 4250DF45 & ABEA303E \\
\hline EBD90AF2 & 1E99300C & 86C5B810 & 6D08B661 & A89881C5 & 25D17EA6 & 0ECBA874 & 63F53B98 \\
\hline 08BF0E68 & 477CF579 & 6E4E79F6 & D871E636 & 889E2FAB & A53FA658 & 5C6DE651 & 96877234 \\
\hline
\end{tabular}

Untuk menjadwalkan pesan ke 16 sampai 63 dilakukan perhitungan sebagai berikut :

$$
\begin{aligned}
\sigma_{1}^{(256)}\left(W_{i-2}\right) & =\left(\left(W_{i-2}\right) \text { ROTR } 17\right) \oplus\left(\left(W_{i-2}\right) \text { ROTR } 19\right) \oplus\left(\left(W_{i-2}\right) S H R 10\right) \\
\left(\left(W_{16-2}\right)\right. \text { ROTR 17) } & =\left(\left(W_{14}\right) \text { ROTR 17) }=((00000000) \text { ROTR } 17)\right. \\
& =((00000000000000000000000000000000) \text { ROTR } 17) \\
& =(00000000000000000000000000000000) \\
\left(\left(W_{16-2}\right)\right. \text { ROTR 19) } & =\left(\left(W_{14}\right) \text { ROTR } 19\right)=((00000000) \text { ROTR } 19) \\
& =((00000000000000000000000000000000) R O T R 19) \\
& =(00000000000000000000000000000000) \\
\left(\left(W_{16-2}\right)\right. \text { SHR 10) } & =\left(\left(W_{14}\right) \text { SHR } 10\right)=((00000000) \text { SHR } 10) \\
& =((00000000000000000000000000000000) \text { SHR } 10) \\
& =(00000000000000000000000000000000) \\
\sigma_{1}^{(256)}\left(W_{i-2}\right) & =(00000000000000000000000000000000) \\
& (00000000000000000000000000000000)
\end{aligned}
$$




$$
\begin{aligned}
& (00000000000000000000000000000000) \oplus \\
& W_{16-7} \quad=W_{9}=80000000 \\
& \sigma_{0}^{(256)}\left(W_{i-15}\right) \quad=\left(\left(W_{i-15}\right) R O T R 7\right) \oplus\left(\left(W_{i-15}\right) R O T R 18\right) \oplus\left(\left(W_{i-15}\right) S H R 3\right) \\
& \left(\left(W_{16-15}\right) \text { ROTR } 7\right) \quad=\left(\left(W_{1}\right) \text { ROTR } 7\right)=((6962646 \mathrm{E}) \text { ROTR } 7) \\
& =(01101001011000100110010001101110) \text { ROTR 7 }) \\
& =(11011100110100101100010011001000) \\
& \left(\left(W_{16-15}\right) \text { ROTR } 7\right) \quad=\left(\left(W_{1}\right) \text { ROTR } 18\right)=((6962646 \mathrm{E}) \text { ROTR } 18) \\
& =((01101001011000100110010001101110) \text { ROTR 18) } \\
& =(10011001000110111001101001011000) \\
& \left(\left(W_{16-15}\right) S H R 3\right)=\left(\left(W_{1}\right) S H R 3\right)=((6962646 \mathrm{E}) S H R 3) \\
& =((01101001011000100110010001101110) \text { SHR 3 }) \\
& =(00001101001011000100110010001101) \\
& \sigma_{0}^{(256)}\left(W_{i-15}\right) \quad=(00001101001011000100110010001101) \\
& =\left(\begin{array}{l}
11011100110100101100010011001000) \\
(100110011000110111001101001011000
\end{array}\right) \\
& =(10011001000110111001101001011000) \\
& =\frac{(00001101001011000100110010001101)}{(01001000111001010001001000011101)} \\
& =48 E 5121 D \\
& W_{16-16}=W_{0}=4 \mathrm{~F} 606 \mathrm{~F} 69 \\
& W t \quad=\sigma_{1}^{(256)}\left(W_{i-2}\right)+W_{i-7}+\sigma_{0}^{(256)}\left(W_{i-15}\right)+W_{i-16} \\
& W t \quad=00000000+80000000+48 \mathrm{E} 5121 \mathrm{D}+4 \mathrm{~F} 606 \mathrm{~F} 69=118458186
\end{aligned}
$$

\begin{tabular}{|c|c|c|c|c|c|c|c|c|}
\hline & $a$ & $b$ & $c$ & $d$ & $e$ & $f$ & $g$ & $h$ \\
\hline Init & 6A09E667 & BB67AE85 & 3С6ЕF372 & A54FF53A & 510E527F & 9B05688C & 1F83D9AB & 5BE0CD19 \\
\hline$t=0$ & 4B68F7B6 & 6A09E667 & BB67AE85 & 3С6EF372 & E828520B & 510E527F & 9B05688C & 1F83D9AB \\
\hline$t=1$ & C040451D & 4B68F7B6 & 6A09E667 & BB67AE85 & 048E9261 & E828520B & 510E527F & 9B05688C \\
\hline$t=2$ & 42F71079 & C040451D & 4B68F7B6 & 6A09E667 & 5A2B7383 & 048E9261 & E828520B & $510 \mathrm{E} 527 \mathrm{~F}$ \\
\hline$t=3$ & F3775F85 & 42F71079 & C040451D & 4B68F7B6 & 0BEABA02 & 5A2B7383 & 048E9261 & E828520B \\
\hline$t=4$ & 7D5F4096 & F3775F85 & $42 F 71079$ & C040451D & A8C48799 & 0BEABA02 & 5A2B7383 & $048 \mathrm{E} 9261$ \\
\hline$t=5$ & 750571D6 & 7D5F4096 & $\begin{array}{l}\text { F3775F85 } \\
\end{array}$ & 42F71079 & DAE80334 & A8C48799 & 0BEABA02 & 5A2B7383 \\
\hline$t=6$ & 1C1572C1 & 750571D6 & 7D5F4096 & F3775F85 & E37F8375 & DAE80334 & A8C48799 & 0BEABA02 \\
\hline$t=7$ & 1487E900 & 1C1572C1 & 750571D6 & 7D5F4096 & C8BC0893 & E37F8375 & DAE80334 & A8C48799 \\
\hline$t=8$ & 7D87A666 & 1487E900 & 1C1572C1 & 750571D6 & 945C17BB & С8BC0893 & E37F8375 & DAE80334 \\
\hline$t=9$ & 57268678 & 7D87A666 & 1487E900 & 1C1572C1 & FCD879F8 & 945C17BB & C8BC0893 & E37F8375 \\
\hline$t=10$ & 5E97C3DA & 57268678 & 7D87A666 & 1487E900 & $691295 A 0$ & FCD879F8 & $945 \mathrm{C} 17 \mathrm{BB}$ & C8BC0893 \\
\hline$t=11$ & 0D0848ED & 5E97C3DA & 57268678 & 7D87A666 & EB903E41 & 691295A0 & FCD879F8 & 945C17BB \\
\hline$t=12$ & 100F6E37 & 0D0848ED & 5E97C3DA & 57268678 & 09868358 & EB903E41 & $691295 \mathrm{~A} 0$ & FCD879F8 \\
\hline$t=13$ & 53С09C64 & 100F6E37 & 0D0848ED & 5E97C3DA & 06D45027 & 09868358 & EB903E41 & 691295A0 \\
\hline$t=14$ & E7F1D787 & 53С09C64 & 100F6E37 & 0D0848ED & 3FDE26AA & 06D45027 & 09868358 & EB903E41 \\
\hline$t=15$ & 1D0BBC9F & $\begin{array}{l}\text { E7F1D787 } \\
\end{array}$ & 53С09C64 & 100F6E37 & 53B4D175 & 3FDE26AA & 06D45027 & 09868358 \\
\hline$t=16$ & A4D1A5CC & 1D0BBC9F & E7F1D787 & 53С09C64 & 4FD6FC6E & 53B4D175 & 3FDE26AA & 06D45027 \\
\hline$t=17$ & 23159FD9 & A4D1A5CC & 1D0BBC9F & E7F1D787 & 8F3E0941 & 4FD6FC6E & 53B4D175 & 3FDE26AA \\
\hline$t=18$ & 1824717D & 23159FD9 & A4D1A5CC & 1D0BBC9F & FA916F51 & 8F3E0941 & 4FD6FC6E & 53B4D175 \\
\hline$t=19$ & 351AB3AE & 1824717D & 23159FD9 & A4D1A5CC & D5EC9154 & FA916F51 & 8F3E0941 & 4FD6FC6E \\
\hline
\end{tabular}

Demikian seterusnya hingga $W_{63}^{(i-1)}$, di mana i adalah jumlah blok 512 bit.

f. Inisialisasi variabel kerja

Selanjutnya melakukan inisialisasi variabel kerja $a, b, c, d, e, f, g$ dan $h$ di mana setiap variabel diambil dari initial hash value $a=H_{0}(0), b=H_{1}(0), c=H_{2}(0), d=H_{3}(0)$, $e=H_{4}(0), f=H_{5}{ }^{(0)}, g=H_{6}(0), h=H_{7}(0)$. Selanjutnya dilakukan proses komputasi fungsi hash SHA-256 dari $\mathrm{t}=0$ sampai $\mathrm{t}=63$.

Tabel 9. Proses Komputasi Fungsi Hash SHA-256 


\begin{tabular}{|c|c|c|c|c|c|c|c|c|}
\hline & $a$ & $b$ & $c$ & $d$ & $\boldsymbol{e}$ & $f$ & $\boldsymbol{g}$ & $\boldsymbol{h}$ \\
\hline$t=20$ & C6BA4E92 & 351AB3AE & 1824717D & 23159FD9 & BF7D8377 & D5EC9154 & FA916F51 & 8F3E0941 \\
\hline$t=21$ & CCC0AA53 & C6BA4E92 & 351AB3AE & 1824717D & AF98E902 & BF7D8377 & D5EC9154 & FA916F51 \\
\hline$t=22$ & 1ECD262C & CCC0AA53 & C6BA4E92 & 351AB3AE & CF4FE975 & AF98E902 & BF7D8377 & D5EC9154 \\
\hline$t=23$ & 28EC04F1 & 1ECD262C & CCC0AA53 & C6BA4E92 & 8CF37AF4 & CF4FE975 & AF98E902 & BF7D8377 \\
\hline$t=24$ & B45DB1D9 & 28EC04F1 & 1ECD262C & CCC0AA53 & 90AA56FB & 8CF37AF4 & CF4FE975 & AF98E902 \\
\hline$t=25$ & 1052CF9A & B45DB1D9 & 28EC04F1 & 1ECD262C & 0B28ACAA & 90AA56FB & 8CF37AF4 & CF4FE975 \\
\hline$t=26$ & 1250EF94 & 1052CF9A & B45DB1D9 & 28EC04F1 & 4CC736B6 & 0B28ACAA & 90AA56FB & 8CF37AF4 \\
\hline$t=27$ & C78936BD & 1250EF94 & 1052CF9A & B45DB1D9 & A49952EB & 4CC736B6 & 0B28ACAA & 90AA56FB \\
\hline$t=28$ & EFFEB392 & C78936BD & 1250EF94 & 1052CF9A & B134EED7 & A49952EB & 4СС736B6 & 0B28ACAA \\
\hline$t=29$ & D1A7214D & EFFEB392 & C78936BD & 1250EF94 & 3C7AA0A5 & B134EED7 & A49952EB & 4CC736B6 \\
\hline$t=30$ & 522BC667 & D1A7214D & EFFEB392 & C78936BD & BA4B1032 & 3C7AA0A5 & B134EED7 & A49952EB \\
\hline$t=31$ & B99FEEE6 & 522ВC667 & D1A7214D & EFFEB392 & 64CF84CD & BA4B1032 & 3С7AA0A5 & B134EED7 \\
\hline$t=32$ & $0993242 \mathrm{~F}$ & B99FEEE6 & $522 \mathrm{BC} 667$ & D1A7214D & 80F843BA & 64CF84CD & BA4B1032 & 3C7AA0A5 \\
\hline$t=33$ & 21E69895 & $0993242 \mathrm{~F}$ & B99FEEE6 & 522BC667 & 2A6599C7 & 80F843BA & 64CF84CD & BA4B1032 \\
\hline$t=34$ & F6BE3AE3 & 21E69895 & $0993242 \mathrm{~F}$ & B99FEEE6 & 089F570D & 2A6599C7 & 80F843BA & 64CF84CD \\
\hline$t=35$ & A9C2A584 & F6BE3AE3 & 21E69895 & $0993242 \mathrm{~F}$ & 6F50A730 & 089F570D & 2A6599C7 & 80F843BA \\
\hline$t=36$ & 764D4B53 & A9C2A584 & F6BE3AE3 & 21E69895 & D135C12A & 6F50A730 & 089F570D & 2A6599C7 \\
\hline$t=37$ & C0370446 & 764D4B53 & A9C2A584 & F6BE3AE3 & 3929C3B1 & D135C12A & 6F50A730 & 089F570D \\
\hline$t=38$ & 9137 & C0370446 & $764 \mathrm{D}$ & A9C2A584 & 31 & 3929C3B1 & $2 \mathrm{~A}$ & 6F50A730 \\
\hline$t=39$ & 4C88 & 9137D23D & $\mathrm{C} 03$ & 764D4B53 & FB2A62B2 & 59842C31 & 392 & D135C12A \\
\hline$t=40$ & 9B4DD93D & 4C888AFA & 9137D23D & C0370446 & 6A87F24A & FB2A62B2 & 59842C31 & 3929C3B1 \\
\hline$t=41$ & 0F8A9BD6 & 9B4DD93D & 4C888AFA & 9137D23D & 9E586B93 & 6A87F24A & FB2A62B2 & 59842C31 \\
\hline$t=42$ & E83481CF & 0F8A9BD6 & 9B4DD93D & 4C888AFA & F2A6356F & 9E586B93 & 6A87F24A & FB2A62B2 \\
\hline$t=43$ & 0A69EC17 & E83481CF & 0F8A9BD6 & 9B4DD93D & A5707EBB & F2A6356F & 9E586B93 & 6A87F24A \\
\hline$t=44$ & 38CF6F15 & 0A69EC17 & E83481CF & 0F8A9BD6 & C4624A18 & A5707EBB & F2A6356F & 9E586B93 \\
\hline$t=45$ & 81F39880 & 38CF6F15 & 0A69EC17 & E83481CF & 5DF4FDE2 & C4624A18 & A5707EBB & F2A6356F \\
\hline$t=46$ & 03B1C880 & $81 F 39880$ & 38CF6F15 & 0A69EC17 & C4DCB267 & 5DF4FDE2 & C4624A18 & A5707EBB \\
\hline$t=47$ & EA3D5AC0 & 03B1C880 & $81 F 39880$ & 38CF6F15 & 6ED90EB7 & C4DCB267 & 5DF4FDE2 & C4624A18 \\
\hline$t=48$ & 254FCBA5 & EA3D5AC0 & 03B1C880 & 81F39880 & C07E5D48 & 6ED90EB7 & C4DCB267 & 5DF4FDE2 \\
\hline$t=49$ & E367 & 254FCBA5 & EA3D & 03B & 16D4337B & C07E5D48 & $6 \mathrm{EL}$ & C4DCB267 \\
\hline$t=50$ & $15 \mathrm{CB}$ & E367B17D & 2541 & EA3 & C819FFCF & 16D4337B & $\mathrm{C} 07$ & $6 \mathrm{EI}$ \\
\hline$t=51$ & $48 \mathrm{~B} 9$ & 15CB1423 & E36 & $254 \mathrm{~F}$ & C56C92FC & C819FFCF & $37 \mathrm{~B}$ & $\mathrm{C} 07$ \\
\hline$t=52$ & 49293AA8 & 48B9B068 & $15 \mathrm{CE}$ & E367B17D & B4DFCCEF & C56C92FC & FCF & 16D4337B \\
\hline$t=53$ & 521A7A56 & 49293AA8 & 48B9B068 & 15CB1423 & 87F654E4 & B4DFCCEF & C56C92FC & C819FFCF \\
\hline$t=54$ & 651D20DE & 521A7A56 & 49293AA8 & 48B9B068 & 02D1A38B & 87F654E4 & B4DFCCEF & $\mathrm{C} 56 \mathrm{C} 92 \mathrm{FC}$ \\
\hline$t=55$ & AA79B8CE & 651D20DE & 521A7A56 & 49293AA8 & C6E3150E & 02D1A38B & 87F654E4 & B4DFCCEF \\
\hline$t=56$ & 0D6EB7B9 & AA79B8CE & 651D20DE & 521A7A56 & 6A76B22C & C6E3150E & 02D1A38B & 87F654E4 \\
\hline$t=57$ & CC441512 & 0D6EB7B9 & AA79B8CE & 651D20DE & AC93BBDC & $6 \mathrm{~A} 76 \mathrm{~B} 22 \mathrm{C}$ & C6E3150E & 02D1A38B \\
\hline$t=58$ & 39956060 & CC441512 & 0D6EB7B9 & AA79B8CE & 06729F4F & AC93BBDC & 6A76B22C & C6E3150E \\
\hline$t=59$ & EB12A5EA & 39956060 & CC441512 & 0D6EB7B9 & 2F631533 & $06729 \mathrm{~F} 4 \mathrm{~F}$ & AC93BBDC & 6A76B22C \\
\hline$t=60$ & AE321AE6 & EB12A5EA & 39956060 & CC441512 & F38852FA & 2F631533 & $06729 \mathrm{~F} 4 \mathrm{~F}$ & AC93BBDC \\
\hline$t=61$ & EE342801 & AE321AE6 & EB12A5EA & 39956060 & 5A93AEA0 & F38852FA & 2F631533 & $06729 \mathrm{~F} 4 \mathrm{~F}$ \\
\hline$t=62$ & 8FC52F27 & EE342801 & AE321AE6 & EB12A5EA & F005EA8C & 5A93AEA0 & F38852FA & 2F631533 \\
\hline$t=63$ & 7D36E2C0 & 8FC52F27 & EE342801 & AE321AE6 & 2BA3B2A4 & F005EA8C & 5A93AEA0 & F38852FA \\
\hline
\end{tabular}

Untuk $t=0$ lakukan perhitungan sebagai berikut :

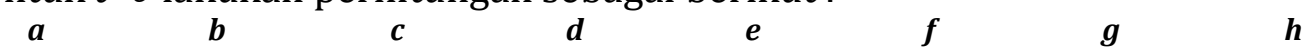

6A09E667 BB67AE85 3C6EF372 A54FF53A 510E527F 9 9B05688C $\quad$ 1F83D9AB 5BE0CD19

$$
\begin{aligned}
T_{1} & =h+\sum_{1}^{(256)}(e)+C h(e, f, g)+K_{t}^{(256)}+W_{t} \\
h & =5 \operatorname{BE} 0 \mathrm{CD} 19 \\
\sum_{1}^{(256)}(e) & =(\text { e ROTR } 6) \oplus(e \text { ROTR 11) } \oplus(e \text { ROTR } 25) \\
(\text { e ROTR 6) } & =(e \text { ROTR } 6)=((510 \mathrm{E} 527 \mathrm{~F}) \text { ROTR } 6) \\
& =((0101000100001110010100100111111) \text { ROTR } 6) \\
& =(1111101010001000011100101001001) \\
(\text { e ROTR 11) } & =(e \text { ROTR 11) }=((510 \mathrm{E} 527 \mathrm{~F}) \text { ROTR } 11) \\
& =((0101000100001110010100100111111) \text { ROTR } 11) \\
& =(01001111111010100010000111001010)
\end{aligned}
$$




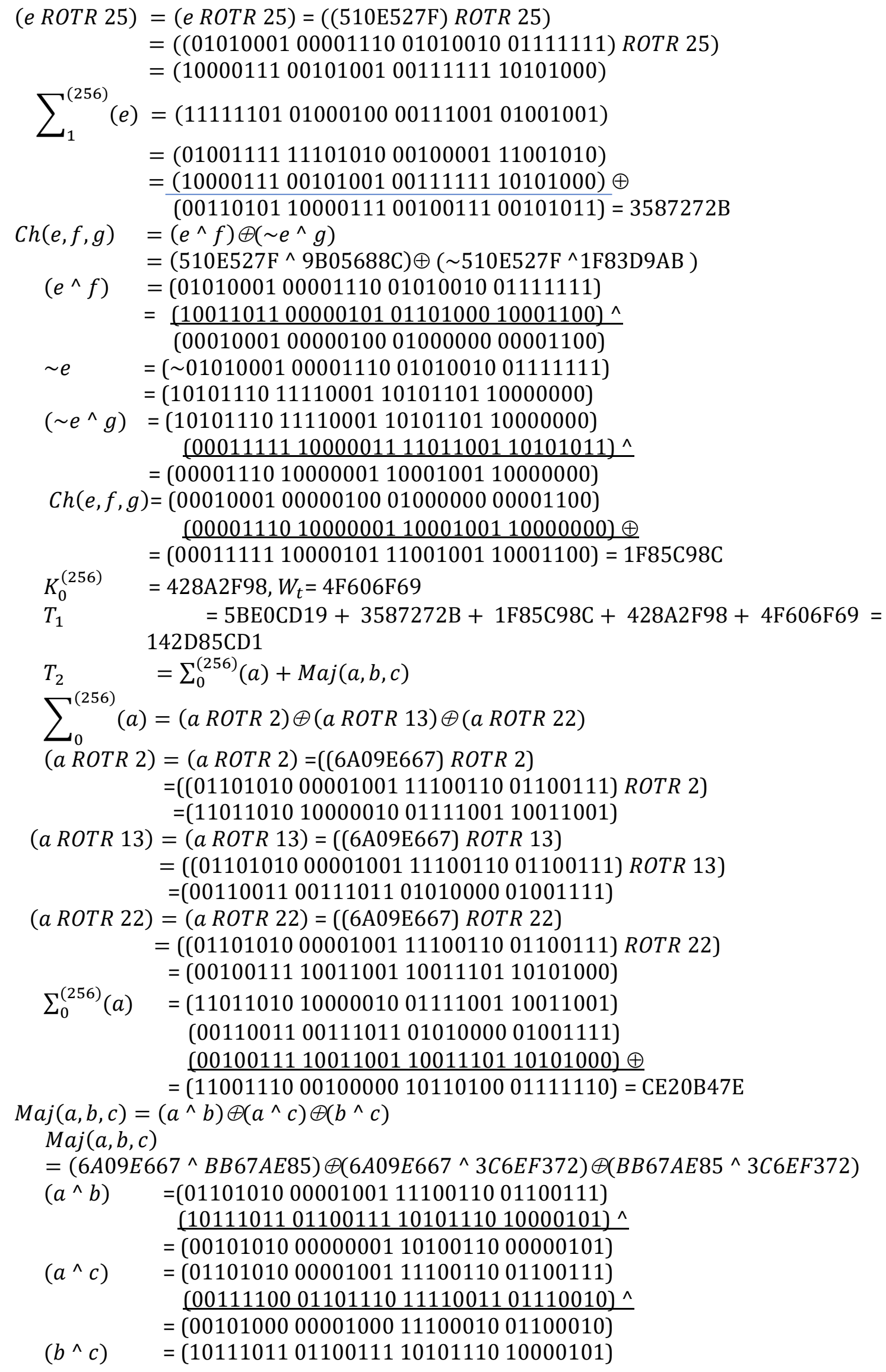




$$
\begin{aligned}
& (00111100011011101111001101110010)^{\wedge} \\
& =\left(\begin{array}{ll}
00111000011001101010001000000000
\end{array}\right) \\
& \operatorname{Maj}(a, b, c)=(00101010000000011010011000000101) \\
& \text { (00101000000010001110001001100010) } \\
& (00111000011001101010001000000000) \oplus \\
& =(00111010011011111110011001100111)=3 \mathrm{~A} 6 \mathrm{FE} 667 \\
& T_{2} \quad=\text { CE20B } 47 \mathrm{E}+3 \mathrm{~A} 6 \mathrm{FE} 667=108909 \mathrm{AE} 5 \\
& h \quad=1 \mathrm{~F} 83 \mathrm{D} 9 \mathrm{AB}, g=9 \mathrm{~B} 05688 \mathrm{C}, f=510 \mathrm{E} 527 \mathrm{~F} \text {, } \\
& e=d+T_{1}=\mathrm{A} 54 \mathrm{FF} 53 \mathrm{~A}+42 \mathrm{D} 85 \mathrm{CD} 1=\mathrm{E} 828520 \mathrm{~B} \\
& d=3 \text { C6EF372, } c=\text { BB67AE85, } b=6 \text { A09E667, } \\
& a=T_{1}+T_{2}=42 \mathrm{D} 85 \mathrm{CD} 1+08909 \mathrm{AE} 5=4 \mathrm{~B} 68 \mathrm{~F} 7 \mathrm{~B} 6
\end{aligned}
$$

g. Menjumlahkan variabel kerja dengan inisial nilai hash

Tabel 10. Penjumlahan dengan initial hash value

\begin{tabular}{|r|c|c|c|c|}
\hline Variabel & Initial Hash Value & & Variabel Kerja & Hasil \\
\hline$H_{0}^{(0)}$ & $6 \mathrm{~A} 09 \mathrm{E} 667$ & + & $7 \mathrm{D} 36 \mathrm{E} 2 \mathrm{C} 0$ & E740C927 \\
\hline$H_{1}^{(0)}$ & BB67EA85 & + & $8 \mathrm{FC} 52 \mathrm{~F} 27$ & $14 \mathrm{~B} 2 \mathrm{D} 19 \mathrm{AC}$ \\
\hline$H_{2}^{(0)}$ & $3 \mathrm{C} 6 \mathrm{EF} 372$ & + & EE342801 & $12 \mathrm{AA} 31 \mathrm{~B} 73$ \\
\hline$H_{3}(0)$ & A54FF53A & + & AE321AE6 & 153821020 \\
\hline$H_{4}^{(0)}$ & $510 \mathrm{E} 527 \mathrm{~F}$ & + & $2 \mathrm{BA} 3 \mathrm{~B} 2 \mathrm{~A} 4$ & $7 \mathrm{CB} 20523$ \\
\hline$H_{5}^{(0)}$ & 9B05688C & + & F005EA8C & $18 \mathrm{~B} 0 \mathrm{~B} 5318$ \\
\hline$H_{6}(0)$ & $1 \mathrm{~F} 83 \mathrm{D} 9 \mathrm{AB}$ & + & $5 \mathrm{~A} 93 \mathrm{AEA} 0$ & $7 \mathrm{~A} 17884 \mathrm{~B}$ \\
\hline$H_{7}^{(0)}$ & $5 \mathrm{BE} 0 \mathrm{CD} 19$ & + & $\mathrm{F} 38852 \mathrm{FA}$ & $14 \mathrm{~F} 692013$ \\
\hline
\end{tabular}

h. Output

Output dari SHA-256 merupakan penggabungan dari $H_{0}{ }^{(0)}$ sampai $H_{7}(0)$ sebagai berikut :

\begin{tabular}{|c|c|c|c|}
\hline Citra & Nilai Hash & Citra & Nilai Hash \\
\hline 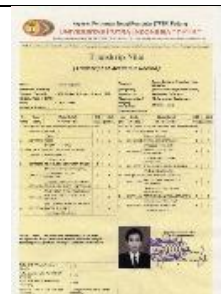 & $\begin{array}{l}\text { CE4C779930278511 } \\
\text { 0CF6C1D447FCEA44 } \\
\text { E139D423C5A8A3E9 } \\
\text { 7F520C992EDD69B5 }\end{array}$ & 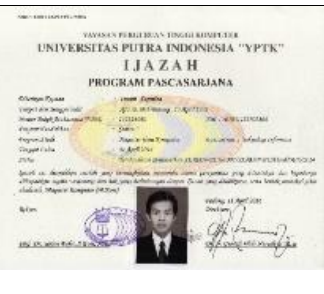 & $\begin{array}{l}\text { 0933DEFC9A55A290 } \\
\text { 633C0820B7EEF706 } \\
\text { 81D03E39A2EBA1B4 } \\
\text { FFABB10F3C66CC23 }\end{array}$ \\
\hline
\end{tabular}

\section{E740C927 || 4B2D19AC || 2AA31B73 || 53821020 || 7CB20523 || 8B0B5318 || 7A17884B || 4F692013}

Sehingga didapat nilai hash dari pesan $\mathrm{M}$ adalah sebagai berikut :

E740C9274B2D19AC2AA31B73538210207CB205238B0B53187A17884B4F69 2013

\subsection{Hasil}

Hasil dari analisa yang telah dilakukan terhadap hasil pemindaian citra ijazah dan transkrip nilai adalah nilai hash 256 bit yang terdiri dari 64 digit bilangan heksadesimal.

Tabel 11. Hasil Nilai Hash 


\subsection{Pengujian}

Pada penelitian ini dilakukan beberapa pengujian pada objek penelitian yaitu citra hasil pemindaian ijazah dan transkrip nilai. Pengujian dilakukan dengan melakukan beberapa manipulasi pada hasil pemindaian citra ijazah dan transkrip nilai dan melihat apakah perubahan yang dilakukan pada citra tersebut juga mengubah nilai hash yang dihasilkan. Apabila nilai hash berubah berarti manipulasi yang dilakukan pada citra tersebut dapat di deteksi oleh fungsi hash SHA-256. Pengujian terhadap citra hasil pemindaian ijazah dan transkrip nilai sebagai berikut:

Tabel 12. Hasil Pengujian

\begin{tabular}{|c|c|c|c|c|c|}
\hline Parameter & Citra Awal & Citra Manipulasi & $\begin{array}{l}\text { Nilai Hash } \\
\text { Citra Awal }\end{array}$ & $\begin{array}{l}\text { Nilai Hash } \\
\text { Citra } \\
\text { Manipulasi }\end{array}$ & Hasil \\
\hline \multirow{15}{*}{$\begin{array}{l}\text { Mengubah } \\
\text { resolusi } \\
\text { citra hasil } \\
\text { pemindaian } \\
\text { ijazah dan } \\
\text { transkrip } \\
\text { nilai }\end{array}$} & 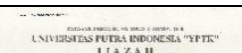 & $=$ & 0933DEFC & EDAC8365 & Terdeteksi \\
\hline & & & 9A55A290 & 27D625F9 & \\
\hline & & & $633 \mathrm{C} 0820$ & B5159002 & \\
\hline & $=5$ & $z=2$ & B7EEF706 & 9F9B2C60 & \\
\hline & 2 & & 81D03E39 & 4341DB3D & \\
\hline & & & A2EBA1B4 & FEBCC091 & \\
\hline & & & $\begin{array}{l}\text { FFABB10F } \\
3 C 66 C 233\end{array}$ & $\begin{array}{l}\text { FEBE5136 } \\
505992 F 5\end{array}$ & \\
\hline & & & CE4C7799 & C28FAE4D & Terdeteksi \\
\hline & & & 30278511 & BB692686 & \\
\hline & & & 0CF6C1D4 & BC997401 & \\
\hline & & & 47FCEA44 & 4CFF2CB9 & \\
\hline & & & E139D423 & 33ADC9E1 & \\
\hline & & & C5A8A3E9 & 25B0EAF7 & \\
\hline & & & 7F520C99 & 78947A4C & \\
\hline & & & 2ED & $\begin{array}{l}\text { CDC7C666 } \\
74 \mathrm{~F} 10 \mathrm{DR} 2\end{array}$ & Tond \\
\hline \multirow{14}{*}{$\begin{array}{c}\text { Mengubah } \\
\text { nilai satu } \\
\text { piksel citra } \\
\text { hasil } \\
\text { pemindaian } \\
\text { ijazah dan } \\
\text { transkrip } \\
\text { nilai }\end{array}$} & & & $\begin{array}{l}\text { 0933DEFC } \\
\text { 9A55A290 }\end{array}$ & $\begin{array}{l}\text { 74F10DB2 } \\
\text { 48058B88 }\end{array}$ & Terdeteksi \\
\hline & & & $633 C 0820$ & 727A2A91 & \\
\hline & & 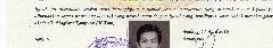 & B7EEF706 & 47D65C8E & \\
\hline & & 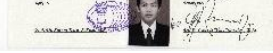 & 81D03E39 & DBB41282 & \\
\hline & & & A2EBA1B4 & 0С529C45 & \\
\hline & & & $\begin{array}{l}\text { FFABB10F } \\
3 \mathrm{C} 66 \mathrm{CC} 23\end{array}$ & $\begin{array}{l}\text { 4C5030AF } \\
\text { DD271727 }\end{array}$ & \\
\hline & & & CE4C7799 & 25385A7D & Terdeteksi \\
\hline & & & 30278511 & E2B6FBF8 & \\
\hline & & & 0CF6C1D4 & C7E76603 & \\
\hline & & & 47FCEA44 & CA7031FF & \\
\hline & $=2$ & & E139D423 & 06F3F936 & \\
\hline & $=0$ & 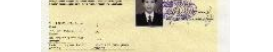 & C5A8A3E9 & D98A369A & \\
\hline & & & 7F520C99 & 59F9608B & \\
\hline & & & 2EDD69B5 & 69B9A9D9 & \\
\hline \multirow{8}{*}{$\begin{array}{l}\text { Mengubah } \\
\text { nilai } \\
\text { brightness } \\
\text { dan contrast } \\
\text { citra hasil } \\
\text { pemindaian } \\
\text { ijazah dan } \\
\text { transkrip }\end{array}$} & inmusara & vervistrty & 0933DEFC & FB7BBAD5 & Terdeteksi \\
\hline & & & 9A55A290 & 5CAAE082 & \\
\hline & - & $-\infty$ & 633C0820 & F2427C99 & \\
\hline & 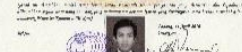 & & B7EEF706 & FB52A0CB & \\
\hline & & & 81D03E39 & 4CADEB32 & \\
\hline & & & A2EBA1B4 & В6B0E69B & \\
\hline & & & FFABB10F & DA5F71C8 & \\
\hline & & & 3С66СС23 & 1B569B98 & \\
\hline
\end{tabular}




\begin{tabular}{|c|c|c|c|c|c|}
\hline Parameter & Citra Awal & Citra Manipulasi & $\begin{array}{l}\text { Nilai Hash } \\
\text { Citra Awal }\end{array}$ & $\begin{array}{l}\text { Nilai Hash } \\
\text { Citra } \\
\text { Manipulasi }\end{array}$ & Hasil \\
\hline nilai & 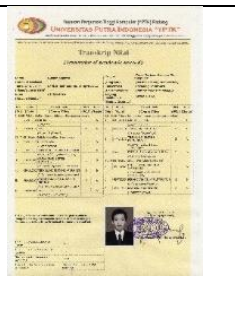 & 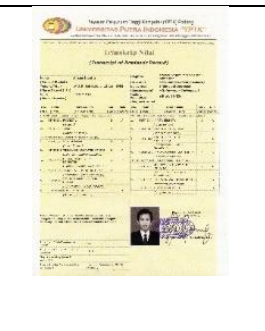 & $\begin{array}{l}\text { CE4C7799 } \\
\text { 30278511 } \\
\text { 0CF6C1D4 } \\
\text { 47FCEA44 } \\
\text { E139D423 } \\
\text { C5A8A3E9 } \\
\text { 7F520C99 } \\
\text { 2EDD69B5 }\end{array}$ & $\begin{array}{l}\text { 4F23F216 } \\
\text { E047B306 } \\
\text { 4F04F53C } \\
\text { FAA126A3 } \\
\text { B9080E0F } \\
\text { 647ADD90 } \\
\text { 9AEFCE22 } \\
\text { 3CFDD87B }\end{array}$ & Terdeteksi \\
\hline $\begin{array}{l}\text { Mengubah } \\
\text { satu } \\
\text { karakter } \\
\text { huruf atau } \\
\text { angka pada } \\
\text { citra hasil } \\
\text { pemindaian } \\
\text { ijazah dan }\end{array}$ & 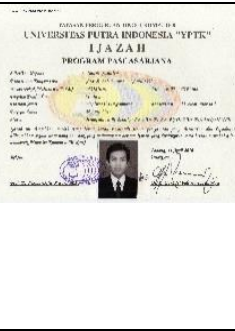 & $\begin{array}{l}= \\
=-1\end{array}$ & $\begin{array}{l}\text { 0933DEFC } \\
\text { 9A55A290 } \\
633 \mathrm{C} 0820 \\
\text { B7EEF706 } \\
\text { 81D03E39 } \\
\text { A2EBA1B4 } \\
\text { FFABB10F } \\
\text { 3C66CC23 }\end{array}$ & $\begin{array}{l}\text { 0D050545 } \\
\text { 964359C4 } \\
\text { 69DBB9D0 } \\
\text { BDF547B4 } \\
\text { 3D16A5E2 } \\
\text { B83C722A } \\
\text { D999911F } \\
\text { 9472FF18 }\end{array}$ & Terdeteksi \\
\hline $\begin{array}{c}\text { transkrip } \\
\text { nilai }\end{array}$ & 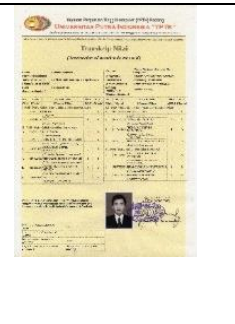 & $\begin{array}{l}D= \\
\overline{D I}= \\
=9 \\
=9\end{array}$ & $\begin{array}{l}\text { CE4C7799 } \\
\text { 30278511 } \\
\text { 0CF6C1D4 } \\
\text { 47FCEA44 } \\
\text { E139D423 } \\
\text { C5A8A3E9 } \\
\text { 7F520C99 } \\
\text { 2EDD69B5 }\end{array}$ & $\begin{array}{l}\text { 3DBD5FE8 } \\
\text { DFD602FE } \\
\text { B2BBDD97 } \\
\text { B066C760 } \\
\text { AAA17383 } \\
\text { B459DC27 } \\
\text { B68F6074 } \\
\text { 8B620179 }\end{array}$ & Terdeteksi \\
\hline
\end{tabular}

Berdasarkan hasil pengujian yang dilakukan pada tabel 12. di atas membuktikan bahwa algoritma SHA-256 berhasil mendeteksi perubahan yang terjadi pada citra hasil pemindaian ijazah dan transkrip nilai dengan persentase hingga 100\%, semua perubahan dapat dideteksi oleh algoritma SHA-256 bahkan perubahan pada satu nilai piksel memberikan perubahan yang sangat signifikan pada nilai hashnya.

\section{KESIMPULAN}

Berdasarkan penelitian yang telah dilakukan maka kesimpulan yang dapat diambil adalah sebagai berikut :

a. Algoritma SHA-256 dapat digunakan untuk mendeteksi orisinalitas citra hasil pemindaian ijazah dan transkrip nilai

b. Algoritma SHA-256 dapat mendeteksi perubahan yang terjadi pada citra hasil pemindaian ijazah dan transkrip nilai walaupun perubahan yang terjadi hanya satu piksel saja

c. Algoritma SHA-256 menghasilkan perbedaan yang signifikan pada nilai hashnya walaupun perubahan yang terjadi pada citra hasil pemindaian ijazah dan transkrip nilai hanya satu piksel saja

\section{DAFTAR PUSTAKA}

[1] A. dan D. S. M. Ghosh, "Review Paper on Secure Hash Algorithm With Its Variants," International Journal of Innovation in Modern Engineering \& Science (IJTIMES), vol. III, no. 05, pp. 1-7, 2017. 
[2] D. Rachamawati, J. T. Tarigan dan A. B. C. Ginting, "A Comparative Study of Message Digest 5 (MD5) and SHA-256 Algorithm," dalam 2nd International Conference on Computing and Applied Informatics 2017, Medan, 2018.

[3] T. Kirubakaran, K. Srinivasan, P. J. Vignesh dan V. V. A, "Implementation of Secure Hash Algorithm-256," International Journal of Engineering Science and Computing (IJESC), pp. 57855788, 2017.

[4] T. Sutoyo, E. Mulyanto, V. Suhartono, O. N. Nurhayati dan W. , Teori Pengolahan Citra Digital, Yogyakarta: Andi, 2009.

[5] D. Putra, Pengolahan Citra Digital, Yogyakarta: Andi, 2010.

[6] R. Munir, Kriptografi, Bandung: Informatika Bandung, 2006.

[7] Y. Kurniawan, Kriptografi Keamanan Internet dan Jaringan Komunikasi, Bandung: Informatika, 2017.

[8] F. I. P. Standards Publications, "Secure Hash Standard," National Institute of Standards and Technology, Amerika Serikat, 2002. 